\title{
Германия - «цифровой аутсайдер»?
}

\author{
E.M. Гапонова \\ Международный союз немецкой культуры \\ Российская Федераџия, 119146, Москва, ул. Малая Пироговская, 5
}

\begin{abstract}
Аннотация. Статья посвящена дигитализации в Германии с учетом исторического контекста. Научная новизна и актуальность исследования заключаются в том, что немецкая цифровая медийная история рассмотрена на фоне трансформации системы СМИ, преимущественно после воссоединения двух германских государств. Научная значимость полученных результатов состоит в том, что представлена и разрешена следующая коллизия. С одной стороны, Германия долгое время причислялась к странам, в которых мультимедиа активно входят в повседневную жизнь, и проблема «цифрового неравенства», вызывавшая бурные дискуссии в мире в середине 1990-х годов, была не характерна для такой экономически развитой страны, как Германия. С другой стороны, в 2018-2019 годах появились научные публикации, в которых страна была представлена как «цифровой аутсайдер», а значит стратегия Федерального правительства по развитию информационнокоммуникативных технологий не была выполнена должным образом. Изучая динамику и перспективы немецкой дигитализации (в историческом, содержательном и экономическом аспектах), автор анализирует сложившуюся ситуацию и в итоге приходит к выводу о ложности предположения об аутсайдерстве.
\end{abstract}

Ключевые слова: Германия, СМИ Германии, дигитализация, политика, массмедиа, цифровое неравенство

\section{Введение}

В начале XXI века Германия взяла курс на создание информационного общества: государство очень быстро осознало потенциал современных коммуникационных технологий и активно поддержало их, в том числе с помощью государственных программ (например, Internet fuer alle). [1. С. 548]. Мультимедийные направления стали активно развиваться, страна вошла в число мировых фаворитов в этой сфере. Однако в последние годы ситуация изменилась, возникло отставание ФРГ по многим параметрам, характеризующим цифровые процессы: адаптивности бизнеса, интеграции цифровых технологий, качеству электронного правительства и цифрового образования. Возникли резонные вопросы: что же случилось, почему замедлилась цифровизация в Германии, включая дигитализацию СМИ, как правительство выходит из кризи-

(C) Гапонова E.M., 2020

(c) (-) This work is licensed under a Creative Commons Attribution 4.0 International License https://creativecommons.org/licenses/by/4.0/ 
са? В статье ответы на эти вопросы даются в соответствии с научными традициями изучения взаимодействия СМИ и политической системы, с опорой на труды российских и немецких авторов о медиасистеме Германии. Эмпирическую базу составили публикации еженедельников «Шпигель», «Штерн», ежедневных газет ФРГ, портала и журнала «Спутник» за разные периоды, а также результаты исследований, проведенных группами Media Perspektiven и Statista.

\section{Изначальный вектор - дигитализация телевидения}

В Германии трансформации в медиасегменте наиболее очевидно проявилась в 1980-х годах, когда резко упали газетные тиражи. Серьезным признаком глобальных изменений стало сокращение объема рекламы в печатных изданиях: за 10 лет (с 2003 года) более чем на 50 \% [2]. В конце 2012 года крупнейшие ежедневные газеты «Франкфуртер Рундшау» и «Файненшл Таймс Дойчланд» объявили о банкротстве [3. С. 364]. Отметим, что граждане ФРГ традиционно предпочитают региональные газеты и малоформатные локальные издания. Новые коммуникационные возможности на рынке массмедиа изменили формы спроса и предложения в медиасфере, что отразилось на деятельности производителей и поставщиков телепрограмм. Например, к 2018 году степень доверия к телевидению в Германии возросла и составила 63 \%, в 2019 году каждый житель государства смотрел телевизор в среднем 236 минут в день [4].

Информационные структуры стали стремиться к скорейшему внедрению новых технологий, чтобы закрепить и увеличить свою долю на рынке. Немецкие газетно-журнальные концерны (например, группы Бертельсмана, Шпрингера, ВАЦ-группа, концерны Бауэра и Бурды) в условиях невероятно быстрого развития мультимедиа смогли утвердиться не только на нащиональном, но и на мировом информационном рынке: они оперативно создавали онлайн-сервисы и электронные версии своих изданий [5]. Поскольку для передачи закодированных цифровых видеосигналов используется широколенточный кабель и цифровые спутники, Германия предприняла определенные усилия в этом направлении. С конца 1980-х годов для интегрирования телекоммуникационных услуг в Германии сделали ставку на ISDN (Integrated Services Digital Network). Осенью 1995 года в стране были задействован функционал первого цифрового спутника (Astra 1 E), а затем спутника Hot Bird 1.

Еще в 1994 году Комиссия по борьбе с монополиями ЕС поставила условие для введения цифрового телевидения: одна и та же компания не может занимать главенствующего положения как при разработке декодера и другой необходимой техники, так и при производстве и продаже программ. Ведущая роль на телерынке Германии долгое время принадлежала двум концернам - Кирха и Бертельсмана. В развитии цифрового телевидения они шли разными путями, но с середины 1990-х работали сообща: решающим фактором стала приватизация Deutsche Telecom AG.

В конце 1995 года первый альянс по разработке цифрового декодера для дигитального ТВ объединил общественно-правовые телерадиокомпании Германии АРД и ЦДФ - по 4,5 \%, частные каналы РТЛ (Германия) и «Канал 
плюс» (Франция) - по 4,5 \%, концерны Бертельсмана и РТЛ (тогда еще не являющегося частью концерна Бертельсмана) - по 9 \%, государственную коммуникационную корпорацию «Дойче Телеком АГ» - 27 \% (до 1996 года). Примерно 37 \% оставались первое время в резерве [6].

\section{Борьба медиаконцернов за лидерство}

Конкурентная борьба продолжалась более десяти лет. Лео Кирх последовал примеру Руперта Мэрдока, который, начиная создавать в Великобритании сеть цифрового платного телевидения BSkyB, купил эксклюзивные права на трансляции футбольных матчей Премьер-лиги. В свою очередь Кирх приобрел права на трансляцию игр Бундеслиги. К середине 1995 года группа Лео Кирха то заявляла о нежелании участвовать в совместном проекте по созданию дигитального телевидения с ведущими информационными концернами, то объявляла, что не будет самостоятельно развивать цифровое телевидение и примкнет к Мультимедийному акционерному обществу (МАО).

В феврале 1996 года сложился новый альянс: руководители канала «Премьере» приняли решение развивать цифровое телевидение на базе своего канала при содействии МАО. В июле того же года программы дигитального телевидения Кирха «Дигиталес фернзеен - 1» (ДФ-1; DF-1 - Digitales Fernsehen - 1) вышли в эфир. Кирх значительно опередил планировавшийся запуск параллельного проекта цифрового телевидения МАО.

Используя свое положение монополиста на рынке интерактивного дигитального телевидения, Кирх стремился привлечь к «ДФ-1» как можно большее количество зрителей. Абонентам были предложены на выбор семнадцать программ: среди них детские каналы Junior и Clubhouse, пять каналов с художественными фильмами (необходимо учесть, что в апреле 1996 года Лео Кирх приобрел права на показ фильмов голливудской кинокомпании Paramount за 1 млрд долл.). Затем последовали и другие приобретения, по оценкам специалистов, общей стоимостью от 6 до 10 млрд марок [7]. К концу 1996 года у «Дигиталес Фернзеен» по плану должно было быть 200 тыс. абонентов, к концу 1997 года - до 1,8 млн. Однако этому не суждено было сбыться. В первый год у «ДФ-1» не появилось и 20 тыс. клиентов, а через тринадцать месяцев после начала старта, не было и 160 тыс.

Первый дигитальный канал нес огромные убытки: не окупились затраты на 1 млн заказанных декодеров, на специально приобретенные в Голливуде лицензии на показ фильмов. Группа Кирха уже не могла в одиночестве позволить себе крупные инвестиции: через год после выхода в эфир потери «ДФ-1» составили около 750 млн марок [8. С. 55]. В марте 1997 года Кирха ожидал новый удар: от сотрудничества и покупки 49 \% акций «ДФ-1» отказался Мэрдок и его канал BSkyB [9]. В августе Кирх официально заявил о скором закрытии канала «ДФ-1» и создании совместно с концерном Бертельсмана и телекоммуникационной корпорацией «Дойче Телеком» нового цифрового ТВ на базе платного канала «Премьере». В новое объединение вошли программы «ДФ-1», «ДСФ» и его технические фирмы.

Концерны Бертельсмана и Кирха приняли решение поделить акции будущего канала «Премьере-Дигиталь» поровну, одновременно договорившись с 
французским каналом «Канал плюс» о выкупе его доли в «Премьере». Бертельсман выразил готовность оплатить половину расходов Кирха на «ДФ-1», а также инвестировать средства в будущий канал (около 2,5 млрд долл.). В Комиссию по монополиям ЕС был отправлен запрос для получения официального согласия на заключение этой сделки, но комиссия отказала, заявив, что подобное объединение двух крупнейших в Германии производителей программ и собственников каналов с телекоммуникационным концерном «Телеком АГ» повредит основам свободной конкурентной борьбы на рынке цифрового телевидения. Казалось, что оба информационных магната попытаются наверстать упущенное. Но этого не случилось: в 2002 году Лео Кирх объявил о своем банкротстве.

\section{Два направления цифровизации ТВ}

Процесс цифровизации происходил на телевидении по двум направлениям: переход на «цифру» и взаимодействие телевещания и интернета, которое побуждало еще более активно развивать рынок видеоконтента. В 2012 году произошло отключение аналогового спутникового сигнала. К этому времени на «цифру» перешли 64,1 \% телезрителей, к концу 2018 года их число составило 99 \%, а на сегодняшний день, согласно данным от 31 июля 2019 года, переход осуществлен полностью (100\%) [10]. Как справедливо отмечает профессор Е.Л. Вартанова, цифровизацию телевидения «можно считать одним из измерений цифровой революции» [11. С. 7], благодаря чему появляется «возможность смотреть телепрограммы с цифровых носителей, получать доступ к вещателям по интернету» [11. С. 9].

С развитием интернета появились и самостоятельные онлайн-СМИ, и агрегаторы: Nachrichten.de, Netzeitung.de, Actuell24.de, Netzpresse.de.

В Германии принято делить онлайн-журналистику на две категории: классическую программно ориентированную и коммуникационно ориентированную.

Программно ориентированная (Senderorientiert) форма онлайн-журналистики берет начало из классических медиа, имеет много общих черт с ними, хотя обладает некоторыми особенностями:

- возможностью комментирования: журналист получает мгновенный отклик;

- краудсорсингом: аудитория помогает при подготовке материала участием в опросах, тестах;

- аудио-слайд-шоу: комбинация из подборки фото со звуковой дорожкой позволяет более наглядно отобразить новость.

Коммуникационно ориентированная форма (Kommunikationsorientiert) подразумевает взаимодействие двух и более пользователей с целью распространения информации. Сюда относятся форумы, чаты, а также блоги и социальные сети. Ее отличительные черты:

- использование блогов, представляющих собой синтез мультимедиадневника с простой системой контент-менеджмента. Один пользователь (или несколько) публикует в своем блоге тексты, видео или аудио - то, чем он хотел бы поделиться с аудиторией, а она в свою очередь комментирует. 
Сейчас блоги все чаще воспринимаются как полноценные медиа, которые к тому же вносят полезный вклад в свободу прессы;

- подкастинг: пользователи выкладывают видео- или аудиовыступления онлайн, оценивают и комментируют друг друга. Это стало аналогом радио и телевидения в интернете;

- легкое получение читателем отклика от редакции с помощью электронной почты;

- использование журналистами и редакцией социальных медиа (Twitter или Facebook) в работе: поиск героев материала или оперативное уточнение деталей.

\section{Эволюция цифровой повестки: признаки отставания}

Как бы трудно не происходило развитие цифровизации, начиная с 2010 года дигитализация стала основным направлением ИКТ-стратегии Федерального правительства «Цифровая Германия 2015». После появления коалиционного договора Христианско-демократического и Христианско-социального союзов (ХДС и ХСС соответственно) и Социал-демократической партии Германии (СДПГ) в декабре 2013 года последовала «Цифровая повестка дня 2014-2017» [12]. Это первый договор, в котором были артикулированы ключевые цели цифровизации, в том числе реализация стратегии «Индустрия 4.0» [13]. В 2014 году канцлер Германии Ангела Меркель объявила, что на тотальную дигитализацию Германии до 2017 года потратят полмиллиарда евро [14]. В марте 2017 года была представлена программа развертывания высокопроизводительных сетей (>50 Мбит/с). Отметим, что к 2014 году это было доступно только для 3/4 германских домохозяйств, а повсеместный высокоскоростной доступ к интернету (50 Мбит/с) вообще отсутствовал. Однако источники и объемы финансирования модернизации не были определены. В 2017 году доля волоконнооптических в совокупных широкополосных подключениях в ФРГ составила 2,1 \% (в 2014 году - 1,1 \%), при этом средний показатель по ОЭСР насчитывал 22,3\% [15]. Былая цель обеспечить скорость 50 Мбит/с выглядела уже неактуальной на фоне целей ЕС - 100 Мбит/с к 2020 году для каждого второго домохозяйства. Такие показатели, как рейтинг цифровой конкурентоспособности, индекс DESI (The Digital Economy and Society Index) [16], Innovationsindikator 2017 свидетельствовали о значительном отставании ФРГ по многим параметрам, характеризующим процессы цифровизации: адаптивности бизнеса, интеграции цифровых технологий, качеству электронного правительства и цифрового образования.

В документе ХДС, ХСС и СДПГ содержалось много обещаний, но было мало конкретики, отсутствовало комплексное видение этого процесса в Германии. 14 ноября 2018 года была провозглашена программа «Интернет 5G и цифровые технологии в каждый дом: правительству Германии есть над чем работать». Это означало, что после долгих лет ожидания правительство Германии снова возвратилось к теме цифровых технологий и их использования в государственном секторе. В коалиционном соглашении этому вопросу посвящена целая глава. 
Перспективы дигитализации, расширение сети [17]. Как отмечалось выше, Федеральное правительство стремится к расширению сети с помощью волоконно-оптических линий связи. Достичь цели планируется к 2025 году, однако процесс идет слишком медленно. По данным Европейской комиссии, только $5 \%$ населения Германии имеет скоростной интернет (более 100 Мб/c). Обеспечение волоконно-оптической связи по всей стране составляет всего 2,3 \%. Для продвижения в данном направлении правительство Германии решило выделить на эти цели около 12 млрд евро. Однако деньги поступают очень медленно, и многие муниципалитеты самостоятельно строят сети. Они хотят от Федерального правительства обеспечения справедливой конкуренции для региональных интернет-провайдеров и упрощения условий на получение лицензии на $5 \mathrm{G}$.

Информационная безопасность и законодательство. На фоне высокого риска хакерских атак на правительственные учреждения корпоративные сети и ключевые инфраструктуры, центр кибербезопасности бундесвера год назад разработали программу централизованного предотвращения подобных угроз. Однако внедрение программы предусматривает расширение полномочий для бундесвера. Многие законы в Германии до сих пор нуждаются в адаптации к цифровым технологиям. Однако ЕС выдвигает одну инициативу за другой, поэтому действия Федерального правительства ФРГ часто противоречивы. Например, внедрение общеевропейского положения о защите данных (DSGVO) плохо подготовлено как на федеральном, так и на земельных уровнях. В вопросе контроля работы цифровые концерны в Германии остаются безнаказанными.

Экономика и наука. Германия существенно отстает в вопросах, связанных с цифровыми технологиями, большинство цифровых продуктов и платформ, которые используются в стране ежедневно, разработаны в США или Азии. Чтобы изменить ситуацию, правительство приняло генеральный план под названием «Искусственный интеллект». В его рамках обещано разработать национальную стратегию обучения и выделить 5 млрд евро для продвижения молодых талантов (Digital Pact\#D).

По данным цифрового объединения Bitkom, в 2017 году оборот в области предприятий Промышленности 4.0 вырос более чем на $20 \%$. «Главная тема - это цифровизация промышленного производства», - говорится в отчете отраслевого объединения [18]. Внушительный рост спроса наблюдается в сфере машиностроения и электроники. Это касается, прежде всего, IT-сервисов, software и hardware. Реализация проекта «Цифровой пакт для школ» должен быть осуществлен в течение пяти лет, речь идет об обновлении цифрового оборудования в учебных заведениях.

Цифровые технологии в госадминистращиях. Услугами E-government пока пользуется всего 19 \% населения Германии. К 2022 году все госадминистрации будут работать в режиме онлайн, благодаря новому закону о доступе к интернету $(\mathrm{OZG})$, который будет возможен в том числе и со смартфона. В развитие этого проекта инвестируется 500 млн евро. Инфраструктура, оборудование и функционирование администрации должны быть модернизированы на всех уровнях. Федеральное правительство впервые устанавливает Bundescloud (об- 
лачный сервис) от поставщика Nextcloud из Штутгарта для взаимодействия различных министерств. Подсчитано, что это программное обеспечение типа open-source экономит расходы на дорогие лицензии (IBM, Microsoft), с которыми прекращаются контракты.

По данным за декабрь 2018 года, доступ к интернету в Германии имели 54 млн чел. (77 \% населения). Особенно активна в сети молодежь: 97,7 \% молодых людей от 14 до 19 лет используют ее регулярно [19. С. 81]. Более половины пользователей получают новости во Всемирной паутине, 62 \% активно взаимодействуют с сервисами «Видео по запросу» (Video on Demand). Самым популярным новостным ресурсом среди немцев является Spiegelonline, электронная версия иллюстрированного информационного еженедельника. Многие классические СМИ Германии конвергентны: у прессы, радиостанций и телеканалов есть сайты в интернете, где наряду с контентом оригинального носителя присутствуют эксклюзивные материалы с мультимедийными элементами.

Популярность набирают платформы Video on Demand. B 2019 году ими воспользовались 39,8 \% всех пользователей интернета. На первом месте YouTube c показателем 39,5 \%, на втором - медиатеки общественноправовых телеканалов (35,6 \%), на третьем - Netflix (26,8 \%), на четвертом Amazon Video (25,4 \%), на пятом - медиатеки частных телеканалов (23,6 \%). В 2019 году Amazon от общего количества пользователей портала в платном режиме использовали $68 \%$, Netflix - $57 \%$, YouTube - $23 \%$.

Медиатеки - особое проявление цифровизации немецкого телевидения. Каждый из телеканалов на сайте имеет отдельную вкладку Mediathek. B них можно посмотреть определенные передачи, которые выходили в эфир, также в любое время доступен прямой эфир телеканала. Но, к сожалению, в медиатеке можно найти не весь контент. Это сделано специально для того, чтобы популярность нелинейного телевидения резко не вырастала на фоне линейного телесмотрения.

Начиная с 2016 года в Германии обсуждается программа «Стратегия дигитализации - 2025» (Digitale Strategie 2025), которую на ежегодной выставке CеВIT (Ганновер, 14-16 марта 2016 года) предложил тогдашний министр экономики страны Зигмар Габриэль. Именно этот документ, названный «Десять шагов в будущее» и охватывающий все сферы общественной жизни - экономику, систему образования, инфраструктуру и рынок труда, должен заменить программу, разработанную Межправительственным агентством по дигитализации. Некоторые считают, что Габриэль использовал ситуацию перед грядущими федеральными выборами, другие рассматривали ее как помощь в решении проблемы цифрового неравенства в сельской местности Германии. Как бы там ни было, «Цифровая стратегия 2025», подготовленная Федеральным министерством экономики и энергетики, провозгласила новую цель - «Стратегию будущего “Гигабитная Германия”», акцентирующую внимание на создании сетевой инфраструктуры.

На данный момент время, скорость и качество подключений, а также технологии, которые их обеспечивают, делают Германию цифровым аутсайдером, но эта ситуация временная. К тому же страна по-прежнему занимает среди стран 
Организации экономического сотрудничества и развития третье место по количеству фиксированных подключений (32,5 млн) и четвертое по количеству мобильных подключений (64,8 млн).

Вероятно, обострила дискуссию об отставании статья «Почему интернет в России дешевый, а в Германии такой дорогой и медленный?» (Warum ist das Internet in Russland so billig und in Deutschland so teuer und langsam?), опубликованная в декабре 2019 года на сайте новостного агентства Sputnik. Апогеем современной ситуации с цифровизацией в Германии стала статья Рудольфа Бауэра «Дигитализация в пакете коньюнктуры: кризис с короной или кризис капитализма?» (Digitalisierung im Konjunkturpaket: "Corona-Krise" oder Krise des Kapitalismus?), опубликованная на альтернативном сайте NachDenkSeiten в июне 2020 года. Для граждан Германии не секрет, что до сих пор на карте обеспечения страны быстрой мобильной связью остаются белые пятна - прежде всего в сельской местности. И связано это с цифровым неравенством, которое волнует немецких исследователей. Они отмечают, что во всех возрастных, профессиональных и гендерных группах в ФРГ самыми популярными являются интернет и телевидение. Радио и МР3-плееры занимают третье и четвертое места. ПК без интернета лишь на пятом месте.

\section{Заключение}

В немецком языке, как и в русском, не сложилось единого эквивалента английского термина digital divide (по-итальянски divario digitale, по-французски fracture numérique, по-испански brecha digital). Дефиниция, определяемая как цифровое неравенство, на немецком имеет два значения: 1) digitale Kluft (англ. digital gap) - цифровая пропасть; 2) digitale Spaltung (англ. digital divide) - цифровой разрыв. Используются и словосочетания «цифровой барьер», «цифровое разделение», «дигитальная яма», «дигитальный разрыв», «цифровой занавес» [20]. На наш взгляд, говорить о цифровой пропасти между потребителями цифровых услуг в Германии не имеет смысла - этого нет в стране, которая последовательно решает свои проблемы.

В октябре 2019 года Федеральное правительство решило ускорить разрешительные процедуры: объекты недвижимости, принадлежащие федерации, федеральным землям и органам местного самоуправления должны активно использоваться для размещения антенных мачт. Правительство запланировало основать компанию по реструктуризации системы мобильной связи, а в случае необходимости выступить в качестве заказчика. Цель в том, чтобы добиться ведущего положения на международном рынке при развитии системы мобильной связи на базе всеохватывающего обеспечения услугами мобильной сети стандарта 4G. Тем самым намечено выполнить основное условие для введения сверхскоростного стандарта мобильной связи следующего поколения 5G.

В рамках конгресса дигитальных технологий в Дортмунде 29 октября 2019 года в центре внимания были новые цифровые платформы. Федеральный министр экономики Петер Альтмайер представил план по созданию сети облачных хранилищ, а также проект под названием Gaia-X (облачная платформа). 
Хотя в настоящее время есть некоторые трудности, они преодолимы: опыт Германии в реализации процессов цифровизации, что было показано в статье, дает все основания для оптимизма.

\section{Список литературы}

[1] Вороненкова Г.Ф. Путь длиною в пять столетий: от рукописного листка до информационного общества. Национальное своеобразие средств массовой информации Германии. М.: Изд-во Московского университета, 2011.

[2] Emmrich J. Medien-manager diskutieren mit Politikern ueber Zukunft des Journalismus. URL: http://www.derwesten.de/suche/?q=Julia+EmmrichMedien-manager (дата обращения: 15.04.2020).

[3] Орехова O.E. Тенденции развития газетного рынка ФРГ в XXI веке // Вестник ННГУ. 2014. № 2-1. С. 364-367.

[4] Fernsehen // Statista. URL: https://de.statista.com (дата обращения: 15.04.2020).

[5] Rost H. Zehn Thesen zur Zukunft der Zeitung. URL: http://www.blog-cj.de/blog/2010/ 10/21/zehn-thesen-zur-zukunft-derzeitung/ (дата обращения: 10.02.2020).

[6] Die Zeit. 1996, 15 Maerz.

[7] Rhein-Zeitung. 1997, 8 Apr.

[8] Informationen zur politischen Bildung: Massenmedien. Bonn, 1998. No. 260.

[9] Germany-Live. 1997, 7 Maerz.

[10] AGF Videoforschung. Offizielle Website. URL: https://www.agf.de/daten/tvdaten/digitaltv/ (дата обращения: 10.02.2020).

[11] Вартанова Е.Л. Цифровое телевидение и трансформации медиасистем. О необходимости междисциплинарных подходов к изучению современного ТВ // Вестник Московского университета. Серия 10. Журналистика. 2011. № 4. С. 6-26.

[12] Digitale Agenda 2014-2017 / Bundesministerium für Wirtschaft und Energie, Bundesministerium des Innern, Bundesministerium für Verkehr und digitale Infrastruktur. August 2014. URL: https://www.digitale-agenda.de/ (дата обращения: 15.04.2020).

[13] Супян Н. Цифровые цели большой коалиции // Научно-аналитический вестник ИЕ РАН. 2018. № 2. С. 159-167.

[14] Михайлина И. Германия вложит полмиллиарда евро в дигитализацию // Germaniaonline. URL: http://germania-online.ru/politika/politika-detal/datum/2014/10/24/germanijavlozhit-polmilliarda-evro-v-digitalizaciju.html (дата обращения: 10.02.2020).

[15] Deutschlands Zukunft gestalten Koalitionsvertrag zwischen CDU, CSU und SPD 18. Legislaturperiode. URL: https://www.bundesregierung.de/Content/DE/ (дата обращения: 03.05.2020).

[16] IMD World Digital Competitiveness Ranking 2017. URL: https://www.bundesregierung.de/ (дата обращения: 03.05.2020).

[17] Bericht über den Stand der Digitalisierung in Europa 2017 - Länderprofil Deutschland. Shaping Europe's digital future: Germany. URL: https://ec.europa.eu/digital-singlemarket/en/scoreboard/germany (дата обращения: 03.05.2020).

[18] Кутикова Г. Интернет 5G и цифровые технологии в каждый дом: правительству Германии есть над чем работать. URL: ttps:/germania.one/internet-5g-i-cifrovyetehnologii-v-kazhdyj-dom-pravitelstvu-germanii-est-nad-chem-rabotat/ (дата обращения: 05.07.2020).

[19] Media Perspektiven. Basisdaten. Daten zur Mediensituation in Deutschland 2018. Frankfurt am Main, Februar 2019. 
[20] Вороненкова Г.Ф. Цифровое неравенство в парадигме научных дискуссий в Германии // Медиаскоп. 2016. Вып. 4. URL: http://www.mediascope.ru/2200 (дата обращения: 03.05.2020).

\title{
История статьи:
}

Дата поступления в редакцию: 24 марта 2020 г.

Дата принятия к печати: 12 июня 2020 г.

\section{Для цитирования:}

Гапонова E.M. Германия - «цифровой аутсайдер»? // Вестник Российского университета дружбы народов. Серия: Литературоведение. Журналистика. 2020. Т. 25. № 3. C. 542-553. http://dx.doi.org/10.22363/2312-9220-2020-25-3-542-553

\section{Сведения об авторе:}

Гапонова Елена Михайловна, ведущий менеджер Международного союза немецкой культуры, соискатель степени кандидата филологических наук. E-mail: soz@ivdk.ru

DOI 10.22363/2312-9220-2020-25-3-542-553

Research article

\section{Is Germany a "digital outsider"?}

\author{
Elena M. Gaponova \\ International Union of German Culture \\ 5 Malaya Pirogovskaya St, Moscow, 119435, Russian Federation
}

\begin{abstract}
The article is devoted to digitalization in Germany, taking into account the historical context. The scientific novelty and relevance of the study lies in the fact that the German digital media history is examined against the background of the transformation of the media system, mainly after the reunification of the two German states. The scientific significance of the research results is that the following conflict is presented and resolved. On the one hand, Germany has long been ranked among the countries in which multimedia is actively involved in everyday life, and the problem of "digital divide" (digitale Kluft or digitale Spaltung), which caused heated discussion in the world in the mid-1990s not typical for an economically developed country like Germany. On the other hand, in 2018-2019 scientific publications appeared in which the country was presented as a digital outsider, which means that the federal government's strategy for the development of information and communication technologies has not been properly developed. The author studies digitalization in Germany in the following aspects: historical, substantial and economic, making an attempt to analyze the current situation.
\end{abstract}

Keywords: Germany, mass media of Germany, digitalization, politics, digital divide

\section{References}

[1] Voronenkova, G.F. (2011). Put' dlinoyu v pyat' stoletij: Ot rukopisnogo listka do informacionnogo obshchestva. Nacional'noe svoeobrazie sredstv massovoj informacii Germanii [A five-hundred-year-long journey: From a handwritten leaflet to the informa- 
tion society. National identity of the German media]. Moscow, Izd-vo Moskovskogo universiteta Publ.

[2] Emmrich, J. (n.d.). Medien-manager diskutieren mit Politikern ueber Zukunft des Journalismus. Retrieved April 15, 2020, from http://www.derwesten.de/suche/?q=Julia + EmmrichMedien-manager

[3] Orekhova, O.E. (2014). Tendencii razvitiya gazetnogo rynka FRG v XXI veke [Trends in the development of the German newspaper market in the $21^{\text {st }}$ century]. Vestnik of Lobachevsky University of Nizhni Novgorod, (2-1), 364-367.

[4] Fernsehen. Statista. Retrieved April 15, 2020, from https://de.statista.com

[5] Rost, H. (n.d.). Zehn Thesen zur Zukunft der Zeitung. Retrieved February 10, 2020, from http://www. blog-cj.de/blog/2010/10/21/zehn-thesen-zur-zukunft-derzeitung/

[6] Die Zeit. (1996, 15 Maerz).

[7] Rhein-Zeitung. (1997, 8 April).

[8] Informationen zur politischen Bildung (1998). Bonn. No. 260.

[9] Germany-Live. (1997, 7 Maerz).

[10] AGF Videoforschung. Offizielle Website. Retrieved February 10, 2020, from https:// www.agf.de/daten/tvdaten/digitaltv/

[11] Vartanova, E.L. (2011). Cifrovoe televidenie i transformacii mediasistem. O neobhodimosti mezhdisciplinarnyh podhodov $\mathrm{k}$ izucheniyu sovremennogo TV [Digital television and the transformation of media systems. On the need for multidisciplinary approaches to the study of modern TV]. Vestnik Moskovskogo universiteta. Series 10. Zhurnalistika, (4), 6-26.

[12] Bundesministerium für Wirtschaft und Energie, Bundesministerium des Innern, Bundesministerium für Verkehr und Digitale. (2014, August). Infrastruktur Digitale Agenda 2014-2017. Retrieved April 15, 2020, from https://www.digitale-agenda.de/

[13] Supyan, N. (2018). Cifrovye celi bol'shoj koalicii [Digital Coalition Goals]. Scientific and Analytical Herald of the Institute of Europe RAS, (2), 159-167.

[14] Mihajlina, I. (2014). Germaniya vlozhit polmilliarda evro v digitalizaciyu [Germany will invest half a billion euros in digitalization]. Germania-Online. Retrieved February 10, 2020, from http://germania-online.ru/politika/politika-detal/datum/2014/10/24/germanijavlozhit-polmilliarda-evro-v-digitalizaciju.html

[15] Deutschlands Zukunft gestalten Koalitionsvertrag zwischen CDU, CSU und SPD 18. Legislaturperiode. Retrieved May 3, 2020, from https://www.bundesregierung.de/Content/DE/

[16] IMD World Digital Competitiveness Ranking 2017. Retrieved May 3, 2020, from https://www.bundesregierung.de/

[17] Bericht über den Stand der Digitalisierung in Europa 2017 - Länderprofil Deutschland. Shaping Europe's digital future: Germany. Retrieved May 3, 2020, from https://ec. europa.eu/digital-single-market/en/scoreboard/germany

[18] Kutikova, G. (n.d.). Internet 5G i cifrovye tekhnologii v kazhdyj dom: Pravitel'stvu Germanii est' nad chem rabotat' [5G Internet and digital technology in every home: The German government has a lot to work on]. Retrieved July 5, 2020, from https:// germania.one/internet-5g-i-cifrovye-tehnologii-v-kazhdyj-dom-pravitelstvu-germanii-estnad-chem-rabotat/

[19] Media Perspektiven. Basisdaten. Daten zur Mediensituation in Deutschland 2018. (2019, February). Frankfurt am Main.

[20] Voronenkova, G.F. (2016). Cifrovoe neravenstvo v paradigme nauchnyh diskussij v Germanii [Digital Inequality in the Paradigm of Scientific Discussion in Germany]. Mediaskop (issue 4). Retrieved May 3, 2020, from http://www.mediascope.ru/2200 


\section{Article history:}

Received: 24 March 2020

Revised: 2 May 2020

Accepted: 12 June 2020

\section{For citation:}

Gaponova, E.M. (2020). Is Germany a "digital outsider"? RUDN Journal of Studies in Literature and Journalism, 25(3), 542-553. (In Russ.) http://dx.doi.org/10.22363/2312-92202020-25-3-542-553

\section{Bio note:}

Elena M. Gaponova, leading manager of the International Union of German Culture, candidate for a degree of PhD in Philology. E-mail: soz@ivdk.ru 